\title{
El cuerpo en el arte como metáfora de la violencia
}

\author{
The body in art as metaphor of violence
}

\begin{abstract}
Resumen: El cuerpo del hombre contemporáneo se expresa por medio de un discurso en constante transformación y las expresiones escénicas son manifestaciones para su análisis e interpretación. El cuerpo sintetiza en sus procesos de creación elementos substanciales de la violencia y deja al descubierto a un sujeto fragilizado que arrastra heridas como producto de sus vivencias. La violencia ha dado paso a la culpa y la vergüenza, emociones morales que han marcado profundamente al ser contemporáneo.
\end{abstract}

Palabras clave: cuerpo, expresión, creación, violencia, fragilidad, sujeto.

\author{
CLAUDIA CAPRILES SANDNER*
}

\begin{abstract}
The body of a contemporary person expresses itself through an ongoing narrative in constant transformation and scenic expressions are manifestations for its analysis and interpretation. The body in its processes of creation synthesizes substantial elements of violence and uncovers a fragile subject that carries wounds as a consequence of his /her experiences. Violence engenders culpability and shame, moral emotions that have profoundly marked contemporary beings.
\end{abstract}

keywords: body, expression, creation, violence, fragility, subject.

El mundo no encontraba nada sagrado en la abstracta desnudez del ser humano.

(Hannah Arendt)

La noción estética del cuerpo se ha modificado dramáticamente en la contemporaneidad. El cuerpo entendido desde la fragmentación de sus partes, propone una noción distinta del esquema corporal alejada de la idea de unidad. Conformado por sus segmentos determinados, es un cuerpo de-construido. Se trata de un cuerpo cuyo valor opera por el significado de cada una de sus partes, cuya consistencia como conjunto integrado ha perdido vigencia y que se revela a través de significados que requieren de una nueva interpretación simbólica.

Fecha de recepción: 10/06/2016. Fecha de aceptación: 27/07/2016.

* Profesora Asociada en la Universidad Nacional Experimental de las Artes (Venezuela), academico@unearte. edu.ve. Licenciada en danza escénica con estudios superiores en composición coreográfica en Folkwang Kunst Universität Essen, Alemania. En 2015 concluye el Máster en pensamiento filosófico contemporáneo en la Universidad de Valencia, España. Bailarina, coreógrafa e investigadora reflexiona en torno a la condición del ser desde la experiencia corporal y su consideración social e histórica. Autora de: (2006) : La danza involuntaria de mi voz. Barnsley, Capriles, Carvajal y otros, La danza y la palabra. Instituto Universitario de Danza. Caracas. (2011): La improvisación, sueño transformador. Revista Danzaluz N 14 . Universidad del Zulia. Maracaibo. 
El cuerpo en la actualidad se expresa por medio de un discurso en constante y veloz transformación. ${ }^{1}$ A partir de dicha complejidad, el sujeto contemporáneo intenta responder por medio de su corporeidad a las interrogantes en torno a la identidad, a la subjetividad, y a las diversas posibilidades de comprender los vínculos consigo mismo y con el cuerpo público, quiere decir, con el entorno social y cultural. Sin embargo, esa acelerada transformación es justamente uno de los problemas que dificulta el análisis teórico del cuerpo en sus múltiples dimensiones expresivas.

En el arte, y en particular en las expresiones escénicas como el teatro físico y la danza contemporánea, así como en aquellas expresiones corporales como el happening, el performance y la acción, se abre un lugar para la observación, el análisis y la interpretación del cuerpo. Esa materia propia, volumen corporal, espacio interno y externo de cada sujeto que se expresa hoy como el resultado de sistemáticas rupturas conceptuales en la historia reciente. Diversas manifestaciones creativas dadas luz al inicio del siglo XX se desarrollaron desde la expresión corporal. El cuerpo ganó protagonismo, se hizo eje fundamental de las investigaciones de artistas y creadores. Preocupaciones que no surgieron como propuestas estéticas alternativas, sino más bien como un medio inexorable para abordar problemáticas en torno al sujeto y su fragilidad ante un mundo acelerado, cuyos cambios se han venido produciendo a partir de las acciones generadas por el hombre en el afán del dominio a sus congéneres. Hoy podemos observar desde estos espacios de creación como ha transcurrido esa especie de metamorfosis en la concepción del cuerpo y las diversas formas de representación que nos hablan de como se entiende este sujeto contemporáneo que habita hoy el mundo. Estos cambios se han suscitado bajo el signo de la violencia. Una violencia presente en los más relevantes acontecimientos de la historia a lo largo del siglo pasado. Una violencia generada desde los cuerpos y hacia los cuerpos y que ha determinado un patrón de conducta que ha servido como mecanismo de transformación y de adaptación del ser y de las sociedades. Los espacios generados por el arte han proporcionado los escenarios para romper los límites y proponer desde otro lugar una mirada distinta del mundo. A partir de la acción poética del cuerpo estos procesos creativos han intentado dar respuestas a algunos enigmas de la condición del hombre moderno.

La danza, al igual que ciertas manifestaciones cuya expresión se produce a través de la experiencia corporal han constituido un espacio de rebeldía; de planteamientos radicales, y uno de los motivos esenciales es justamente la presencia del cuerpo como herramienta substancial para expresar las ideas y las emociones. El discurso desde el cuerpo es un acto efímero. Este expresa con su volumen, su peso, su sistema, sus órganos, sus sentidos, su voz si es necesario, su existencia toda. A través de su materia fluyen las emociones ordenadas con el propósito de comunicar una idea, allí, bajo la luz pública y desde la transparencia de la experiencia en el aquí y el ahora. Analicemos algunos de los mecanismos de esa relación del sujeto y la violencia y como se revela a través del cuerpo en el arte.

El término «violencia», refiere al daño ejercido sobre las personas por parte de otros seres humanos. Pero la violencia es un concepto mucho más complejo, la historia de la humanidad se describe a partir de acontecimientos violentos, las experiencias totalitarias del siglo XX ampliaron el concepto de este término a partir de la implementación de

1 Véase: BAUDRILLARD, Jean (1980) : El intercambio simbólico y la muerte, pp. 117/122 Monte Avila Editores, Caracas. 
aterradoras e innovadoras herramientas para administrarla. El impacto de estas acciones impusieron nuevos criterios desde donde reflexionar en torno a la existencia del hombre y de las sociedades. Para Hannah Arendt, la violencia puede parecer una forma de ejercicio del poder, sin embargo el punto de partida de Arendt en su texto "Sobre la violencia" 2 consiste en el estudio minucioso de la violencia política desde la experiencia histórica reciente. Su mirada que parece dirigirse hacia una crítica de la moral, describe, valorando y analizando la relación entre los medios y los fines de las acciones asociadas a la violencia. Arendt le interesa distinguir entre la violencia como poder, la violencia como dominación, y la violencia como banalidad. Establece una relación tridimensional y aborda el fenómeno desde varios aspectos: El cuerpo social, el cuerpo histórico, el cuerpo político. En el arte contemporáneo el cuerpo aparece como experiencia que sintetiza en sus procesos de creación elementos substanciales de la violencia en todas estas dimensiones; claro esta, que se trata de un abordaje desde la estética propia de cada manifestación, pero propone por medio del lenguaje mudo del gesto y con la presencia viva del cuerpo, reflexiones esenciales sobre la conducta del sujeto; esta condición impermanente, itinerante e inmediata de la acción corporal, con todas sus posibilidades expresivas, movimientos que fuertes o suaves, lentos o rápidos, concéntricos o excéntricos, aparecen con una cierta e innegable violencia dejando al descubierto y descarnado al sujeto contemporáneo en su fragilidad, mostrando sus emociones morales y sus ideas del mundo.

La violencia es un fenómeno poderoso que ha sido a lo largo de la historia de la cultura, el arma predilecta para el dominio del hombre por el hombre y la sociedad. El cuerpo ha sido objeto de la violencia desde las mas antiguas culturas. Sistemáticamente maltratado y humillado, utilizado para fines políticos precisos, cosificado, ha quedado relegado, saqueado, disociado. Ha sido por tanto conveniente negarlo en el esfuerzo de sobrevivir al dolor de las heridas. Entender el cuerpo como totalidad, como lugar de la propia existencia en su justa dimensión sagrada, no es precisamente hacia donde ha evolucionado la cultura occidental. El desarraigo simbólico hacia nuestro cuerpo es sintomático de la sociedad contemporánea donde vivimos. En medio de esta compleja relación surge la necesidad de proponer desde el arte investigaciones creativas que re-dimensionan los planteamientos sobre la integridad del sujeto, abordan su fragilidad frente a los acontecimientos de la historia reciente para encontrar los rasgos de una identidad rota. Los procesos creativos desde el cuerpo, movilizan aspectos profundos de la memoria individual y colectiva, en una búsqueda de reparación en el ámbito de la esfera íntima y la esfera ética compartida por medio de la experiencia histórica en un ejercicio de auto conocimiento y reconocimiento.

La fragilidad del ser se materializa en las heridas que arrastra como producto de sus vivencias. La violencia y el sufrimiento, han dado paso a la culpa y la vergüenza, emociones morales que han marcado profundamente al sujeto contemporáneo ${ }^{3}$. Desde la perspectiva de la experiencia del cuerpo, estas vivencias condicionan o influyen fuertemente en su capacidad de relación con los otros y consigo mismo. La esfera ética de este ser escindido por los acontecimientos de nuestra modernidad se ve influenciada y alterada, como una consecuencia de eventos lamentables. Ahora bien, si en un esfuerzo de sobreponerse al sufrimiento el sujeto

2 Véase: ARENDT, Hannah (1970):Sobre la violencia, Alianza, Madrid.

3 Véase: WOLLHEIM, Richard (2006): Sobre las emociones, pp. 243/252, Machado Libros, Madrid. 
contemporáneo da muestras de querer superar sus experiencias pasadas, podemos decir que este deseo también tendrá una influencia y le permitirá abrirse, de cierta, manera hacia los otros. El cuerpo como territorio ético individual se abre a través de su expresión y por medio del territorio de la creación artística y en especial desde las manifestaciones que proponen sus discursos desde el cuerpo.

Tiempo, espacio y energía conforman los elementos primarios que confluyen en las expresiones corporales escenificadas. Cuando estos componentes se organizan fuera de los límites convencionales del arte, surgen innumerables formas subversivas que desafían las relaciones tradicionales de la temporalidad, proponiendo por ejemplo una discontinuidad lineal, o una traslocación del espacio, usando como recurso la singularidad del lugar. Elementos que generan el colapso de la relación habitual entre intérprete y público. Así, este tipo de propuesta, provoca en artistas y espectadores una reflexión en torno a los límites que ordenan las cosas del mundo.

A finales del pasado siglo, un grupo de artistas estadounidense dedicados al estudio del movimiento, comenzaron a proponer un conjunto de revolucionarios conceptos desde donde mover el cuerpo para expresar sus inquietudes ante un mundo cada vez más global, este movimiento conocido inicialmente como danza posmoderna y mejor entendido a mi manera de ver como nueva danza, tuvo sus orígenes antes, durante la década de los sesenta en plena convulsión social. En medio de la experiencia de la guerra de Vietnam y la lucha por diversas reinvindicaciones de los derechos civiles, surge este interesante movimiento en Nueva York $^{4}$. En Europa, concretamente en la ciudad de Wuppertal, Alemania; Pina Bausch ${ }^{5}$ desde mediados de los años setenta, desnudaba los procesos creativos exponiendo a los sujetos vulnerables frente al público, desarrollando sus composiciones a partir de arriesgadas improvisaciones. Bausch pregunta a los bailarines, quienes responden con acciones intimas que revelan emociones difíciles de expresar con la palabra, sus cuerpos en movimiento muestran con certeza, la existencia impermanente del hombre, el futuro escindido y la presencia de la muerte. Sus obras recogen con una potencia inexorable las emociones morales que describen con espeluznante precisión la condición humana, el desamor y el conflicto de las relaciones humanas en medio de la guerra fría y como consecuencia de los dramáticos vestigios de la segunda guerra mundial. Ciertamente el cuerpo ya había aprendido desde los visionarios precursores de principios del siglo XX a moverse desde otros impulsos fuera de toda norma de la academia clásica. Efectivamente la danza y las artes corporales se emanciparon de sus propias reglas, estas impuestas desde las tradicionales formas. A este espacio de libertad creadora se sumaron artistas de otras manifestaciones, de otras expresiones de la vanguardia europea, norteamericana y latinoamericana.

4 Un nutrido grupo de artistas que reaccionaron a los postulados de la danza moderna académica implantada por Martha Graham, Doris Humphrey, Ted Shaw y Ruth St Denis, se reunían en la Judson Memorial Church en la década de los sesenta y allí revolucionaron las propuestas artísticas y creativas del arte del movimiento, La denominada nueva danza. Entre los representantes de este movimiento se encuentran Anna Halprins, Trisha Brown, Steve Paxton, Simone Forti, Joan Skinner entre muchos otros artistas relevantes que contribuyeron a la investigación del cuerpo y del movimiento danzado.

5 Pina Bausch coreógrafa y bailarina alemana, nacida en Solingen en 1940, estudio en la Folkwang Schule Essen y posteriormente en la escuela Julliard de Nueva York. Trabajo y estudio con Kurt jooss y se destaco por su enorme producción de obras de danza teatro como creadora y directora del Wuppertal Bûhne. Transformó radicalmente el lenguaje escénico de la danza. Murió en Wuppertal en 2009 dejando un legado impresionante de más de 30 obras. 
Así, estas innovadoras propuestas rompen la relación típicamente modernista al exponer sus acciones en espacios no convencionales, espacios públicos y escenarios naturales. Se produce un cambio fundamental del sentido político de la acción. Las acciones son generadas a partir de improvisaciones en el lugar, abriendo nuevas oportunidades para investigar los límites entre el arte y la vida, el cuerpo y la experiencia. La acción corporal pasa de poseer un contenido ético a convertirse en un acto ético en sí. Vemos que de pronto la obra no relata una historia, no explica un discurso, si no más bien produce a través de la propia acción corporal un contenido que emerge de si misma. El cuerpo comienza a revelarse por medio del arte. Nace un lenguaje propio y libre, expresado a través de la soltura de las articulaciones y la exploración de las funciones orgánicas, aparece una interesante tensión entre el impulso propio de la emoción, expuesto por medio de los gestos y movimientos ondulatorios de la columna vertebral, frente a la razón como fundamento del hombre vertical.

Ahora bien, por qué y para qué se mueve el cuerpo en el espacio. Las propuestas de lo que se considero el período de la danza posmoderna analítica, consistieron en experimentos en espacios alternativos como iglesias, galerías, calles y estacionamientos. Investigaron a partir del estudio de los movimientos de los transeúntes, incluyendo en ocasiones cuerpos de personas anónimas que eran integradas en la obra. Merce Cunnigham ${ }^{6}$ por ejemplo, exploró en el conjunto de su obra coreográfica, con especial interés, la relación del cuerpo con el espacio y el encuentro aleatorio entre los cuerpos, en sus trabajos se aprecia por medio de la abstracción una exaltación de los sentidos y de las ideas fundamentales sobre el tiempo, el espacio y la soledad del individuo.

La exposición de un cuerpo solitario, específicamente iluminado en un espacio escénico vacío de objetos y otros sujetos, es en cierta manera la contundente expresión de este sujeto fragilizado, propio de la contemporaneidad. Imaginemos como progresivamente entran otros cuerpos con la misma condición y el espacio se va ocupando sucesivamente. ¿Pueden acaso esos cuerpos reconocerse? Ciertamente, eso sería muy posible. Pero si lo hacen, ¿Son capaces de aceptarse mutuamente? Estos cuerpos que se mueven en el espacio desde su peculiar soledad muestran rasgos de su propia fragilidad. En un esfuerzo de precisión, podría decirse que un sujeto fragilizado es aquel, que tras la vivencia del horror, del sufrimiento y la violencia mantiene dentro de sí una especie de incertidumbre en cuanto a su lugar en el mundo, a su pertenencia a un determinado grupo y a su capacidad para compartir sus vivencias personales. Se trata, en suma, de sujetos que arrastran, como un fardo, sus esferas éticas personales -es decir, sus vivencias individuales sobre la violencia y el sufrimiento-, y que en la obra coreográfica se expresan por medio de la forma de ordenar los cuerpos en el espacio y las secuencias individuales de movimientos de cada cuerpo en su espacio interno, quiere decir, ese espacio propio determinado por los límites de la piel y su espacio periférico entendido como la esfera que alcanzan las extremidades de cada cuerpo.

Por otra parte, y esta es una cuestión medular, ¿Qué hay de aquellos, que sin haber sufrido en su carne el oprobio de la violencia, pueden considerarse a salvo?, probablemente se encuentran sumidos en la culpa. Sujetos que al salvarse también fueron lastrados por la

6 Merce Cunningham, coreógrafo y bailarín norteamericano. Creó sus obras coreográficas desde la máxima pureza explotando las más extremas posibilidades del color, la luz y el sonido, trabajo en colaboración con creadores fundamentales como Robert Rauschenberg y Andy Warhol y de manera muy estrecha con John Cage. Muere en el 2009 a la edad de 90 años. 
carga de una culpa futura, y es con esta herencia con la que deben seguir transitando en la esfera ética pública en busca del reconocimiento. El sujeto de estos tiempos posee una sensación de discontinuidad dramática con el pasado, afectado por una sentimiento de inquietud de cambio debido a una ruptura en el sentido de conexión entre su ser y los símbolos vitales de su tradición cultural. Una dislocación histórica marcada por cambios violentos y acciones violentas. El cuerpo es entonces un mapa expresivo de esas experiencias radicales.

Otras expresiones artísticas corporales exploraron como objetivo el movimiento natural biomecánico, como caminar, reptar, rodar, utilizando la determinación espontánea y el azar como una metáfora de la libertad, a veces los experimentos promovieron la integración de elementos absurdos heterogéneos incorporados en una estructura no lineal con gestos cotidianos para producir por medio del contraste y del absurdo la reflexión inmediata del espectador. Se aborda el problema de la repetición de un gesto, movimiento o secuencia. En ocasiones se presenta el cuerpo como un volumen-objeto, o se incorpora la voz como elemento corporal, así también se utilizan recursos para poner el cuerpo en una relación extraordinaria con el espacio y retando la fuerza de gravedad 7 . El objetivo no es otro que señalar y subrayar por medio de la transgresión de las formas convencionales del arte y de las reguladas conductas corporales, la realidad interna de estos cuerpos fragilizados para evidenciar las heridas de la violencia, así los procesos de creación en estas obras utilizan en ocasiones técnicas que llevan a la ruptura de los límites físicos y psíquicos, quiere decir que se somete al interprete a cierta violencia como una forma de re-edición de la realidad y como mecanismo para acceder a la memoria emotiva del intérprete.

La violencia es acción, y por tanto requiere de herramientas para actuar y la verdadera sustancia de la acción violenta está caracterizada, en tanto al aspecto humano, por el hecho de que el fin puede ser superado por los medios, a los que justifica y que son necesarios para alcanzarlo. Los resultados de la acción violenta sobrepasan el control de aquel que produjo la acción, la violencia se apoya en herramientas emocionales y su blanco es el cuerpo, posee una arbitrariedad en tanto es más efectiva cuando es inesperada ${ }^{8}$. Parte de su potencia está asociada a su condición performática y por tanto no hay certidumbre. La acción violenta irrumpe, y aparentemente no sigue patrones regulares. El miedo es en este sentido una herramienta útil; involuntario y arcaico, genera en el individuo múltiples e impredecibles efectos. Sabemos que el miedo es el resultado de acciones violentas, pero otras veces es lo que les da origen. Es una emoción sólida y potente, acontece a nivel de la corteza cerebral, y no afecta únicamente la mente sino que se extiende hacia los órganos vitales, pulmones, hígado, intestinos, y por supuesto, el corazón. A partir de esa experiencia corporal reaccionamos, prestamos toda la atención para comprender lo que sucede, y cada uno; a partir de su propia memoria emotiva, puede experimentar más o menos miedo; los pensamientos rápidamente se ajustan frente a la situación y de alguna manera se produce una adaptación dada por la necesidad de sobrevivir.

7 Lucinda Childs en 1964, propone una pieza que crea una juego entre presencia (su voz) y ausencia (su cuerpo), y entre el pasado (lo que era previamente grabada) y presente. Trisha Brown creo, por ejemplo obras como "El hombre caminando por el lado de un edificio" (1970) en esta obra icónica la artista caminaba por el lado de un edificio en Soho, con la ayuda de arneses, desafiando la gravedad y transformando la relación del cuerpo en el espacio.

8 Véase: ARENDT, Hannah (1970): Sobre la violencia, Alianza, Madrid. 
Los cambios adaptativos que se desencadenan a partir del miedo producen efectos violentos en la experiencia corporal, La potencia del miedo puede incluso dejar una huella aunque invisible, indeleble en la memoria. Esa invisibilidad no niega sin embargo una forma de comportamiento corporal, y una expresión del gesto, de la comunicación no verbal que va de todas formas a revelar dicha experiencia. El miedo es una pulsión, es como una substancia que puede tomar muchas formas, que forma parte de los instintos del yo y es fuente de la acción corporal en sentido creativo y también destructivo ${ }^{9}$. El miedo es el punto de partida para el sometimiento, un miedo que va también dirigido asimismo y que guarda una relación con la incapacidad de asumir cada quien su propio destino.

El miedo es parte del instinto de conservación propio del estado de la naturaleza, pero posee otros alcances de tipo simbólico en la experiencia y la expresión del cuerpo contemporáneo. La agresividad que nos convierte en seres malignos no es innata, ni intuitiva, nada tiene que ver con la constitución genética del ser. El mal, definido como la capacidad que posee el ser humano de someter a sus congéneres a actos crueles; no genera, en la mayor parte de los casos, ningún beneficio, ninguna garantía de supervivencia propia, ninguna ganancia apreciable; entonces, ¿porque actúa el ser humano de esta manera?, ¿Porque es este ser racional el más sanguinario y brutal hacia sus semejantes?. La respuesta más inmediata esta vinculada a la noción de poder, en la actualidad se ejerce por medio de la violencia en casi todos los ámbitos, en el pasado se hablaba de autoridad, pero como lo explica Arendt estas tres esferas, independiente una de otra se encuentran relacionadas con la temporalidad, así la autoridad se asocia al pasado, el poder es presente y la violencia el futuro, de allí preocupa su instrumentación en función de un fin que se busca. La violencia es un medio que puede justificarse pero que no tiene una legitimidad. Porque la legitimidad viene de los orígenes, es decir del pasado, pero no de un proyecto futuro basado en la ruptura, de tal manera que las bases de una sociedad pueden ser más o menos democráticas; pero. van a hacer uso de un grado de violencia para garantizar su integración y su mantenimiento. El cuerpo en medio de su omnipresencia posmoderna es parte de esta dinámica, en la cuál la violencia es el mecanismo mas efectivo para expresar su existencia dentro de los fenómenos sociales actuales. El conflicto existe y hay que buscar un espacio simbólico para resolverlo.

Los derechos humanos universales hablan de un sujeto, un ser humano, abstracto, que parece que no existe como cuerpo y que parece extraviado y ambiguo, se proponen libertades al tiempo que se subyugan los cuerpos. A lo largo del siglo XX, hemos podido contemplar la horrenda violencia expresada en los cuerpos víctimas de las torturas, de las masacres, del holocausto, de los abusos sexuales y castigos físicos y psíquicos en los campos de trabajo, o en la explotación innombrable de los cuerpos en las empresas multimillonarias trasnacionales. Hoy en día la pobreza y el hambre marcan los cuerpos y los definen. Todo es expresado en la corporeidad. Incluso como espacio de las expresiones individuales, que ya no se concentra en el vestir de las posibilidades de la moda, sino en otros signos, que revelan la búsqueda de identidad y de libertad, pero en donde se observan ritos de violencia, como en el tatuaje, el piercing, la inclusión de prótesis y tecnología y las operaciones estéticas. Nos encontramos ante un cuerpo que como un lienzo, no solo lleva consigo las marcas naturales de la experiencia, sino que es constantemente intervenido por la técnica y además soporta

9 Véase: FREUD, Sigmund (2014): El malestar en la Cultura, pp. Alianza, Madrid. 
las cicatrices del dolor de las acciones violentas. Hemos querido pensar que hay un adentro y un afuera del cuerpo, pero en cambio no consideramos que exista un adentro y un afuera del alma; en el discurso filosófico, mas allá de las ideas de Locke sobre la transferencia de la experiencia sensorial hacia un nivel posterior de reflexión, se sucede una consciencia desde el cuerpo cuando sentimos o vivenciamos una experiencia sensorial. De la que sin duda se podría posteriormente construir una reflexión, Arendt señala "las emociones que se sienten están tan destinadas a manifestarse en su estado inalterado como lo están los órganos internos, gracias a los que vivimos." ${ }^{10}$. Y es que la violencia se expresa en el cuerpo, otras emociones como el amor, se anidan en el alma y aunque están presentes en el cuerpo, no solo se sustentan en él, se conservan bajo las mismas funciones vitales de los órganos internos.

Sobre el escenario vemos a un bailarín que durante largo tiempo se ha preparado para fortalecer sus poderosos músculos, flexibilizar las articulaciones, desarrollar capacidades extraordinarias. Se ha dedicado al minucioso estudio de la biomecánica del cuerpo, de los sistemas de conexión neuromuscular; ha estimulado sus sentidos con el fin de descubrir los mágicos canales que conectan alma, mente y cuerpo, y así desde su poder y su sensibilidad lanzarse a la aventura de expresar en forma extraordinaria las cosas del mundo. El arte desde el cuerpo lanza su mudo discurso hacia el universo, desde el escenario hacia un público. El impacto del gesto que impulsa suele ser violento, sagaz, a veces doloroso, debe acceder a lo extraordinario y para ello moverse desde los más extremos lugares, el cuerpo se mueve dentro de sus estructuras coreográficas con precisión, con consciencia de la tridimensionalidad del espacio, frontal/sagital/transversal; y cada gesto desde la fragmentación actúa en pedazos para expresar la fuerza de una posmodernidad inacabada, dirige la intensidad de la energía desde la sutileza casi imperceptible hasta el fortísimo golpe, cuestionando los límites entre la vida y la muerte. Otras veces del lentísimo desplazamiento que recuerda el pasado hasta la velocidad acelerada de estos tiempos futuros, el cuerpo suspendido desde la fuerza del vientre como centro emana la energía de su vitalidad hacia el universo todo, esparciéndose, para luego recoger, traer y alimentarse del mundo y de los otros. Por ello es un cuerpo real que se hace metáfora de la violencia, todo lo que reúne el mapa de un cuerpo vivido ha sido marcado por la violencia de todos los cuerpos del mundo, por la existencia del dolor inmanente. La expresión de los cuerpos danzantes, con sus propuestas atrevidas, reflejan ese sentir que nos obliga a mirar directamente el dolor de los demás y no voltear en otra dirección para cegarnos ignorando los cuerpos que ya no están.

\section{Bibliografía}

Arendt, Hannah (2012): La vida del Espíritu, Paidos, Barcelona.

Arendt, Hannah (2004): Los afectos Humanos, Paidos, Barcelona.

Arendt, Hannah (1970): Sobre la Violencia, Alianza, Madrid.

Baudrillard, Jean (1976): L'échange symbolique et la mort, Gallimard, París.

Baudrillard, Jean (1980): El intercambio simbólico y la muerte, Monte Avila Editores, Caracas.

Freud, Sigmund (2014): El malestar en la Cultura, Alianza, Madrid.

Wollheim, Richard (2006): Sobre las emociones, Machado Libros, Madrid.

10 Véase: ARENDT, Hannah (2012): La vida del espíritu, pp. 55/67, Paidos, Barcelona. 